\title{
¿TODO TIEMPO PASADO FUE...? Preparado para el II Foro Cuatro Saberes
}

n la década de los años cuarenta, cuando niño, en mi pueblo todo era tranquilidad. En las oficinas la Eduardo Londoño Jaramillo

Universidad Autónoma do Maniedes

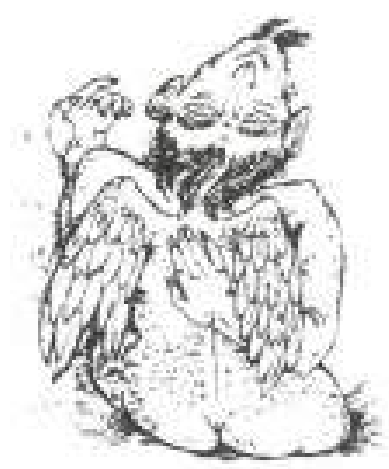
Profeser Facullad de Ecanomia Empresarial

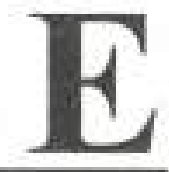

mayor tecnologia estaba representada en un teiéfono de magneto y en una máquina de escribir mecanica, cuyo sonido anunciaba su labor. Desde el alcalde hasta el policia raso eran autoridades que inspiraban credibilidad y respeto. La palabra era una prenda de garantia: no se necesitaba autenticarla. Se podia transitar, de dia o de noche, por cualquier carretera o camino veredal sin que se llegase a pensar que algo malo pudiese suceder; únicamente el temor a los "espantos" o a la "patasola". Los portones de las casas permanecian abiertos durante el dia. En los campos la tecnologia era nula, pero a los moradores no les faltaba qué comer. Las personas estaban prestas a cualquier servicio cuando la comunidad era convocada. 


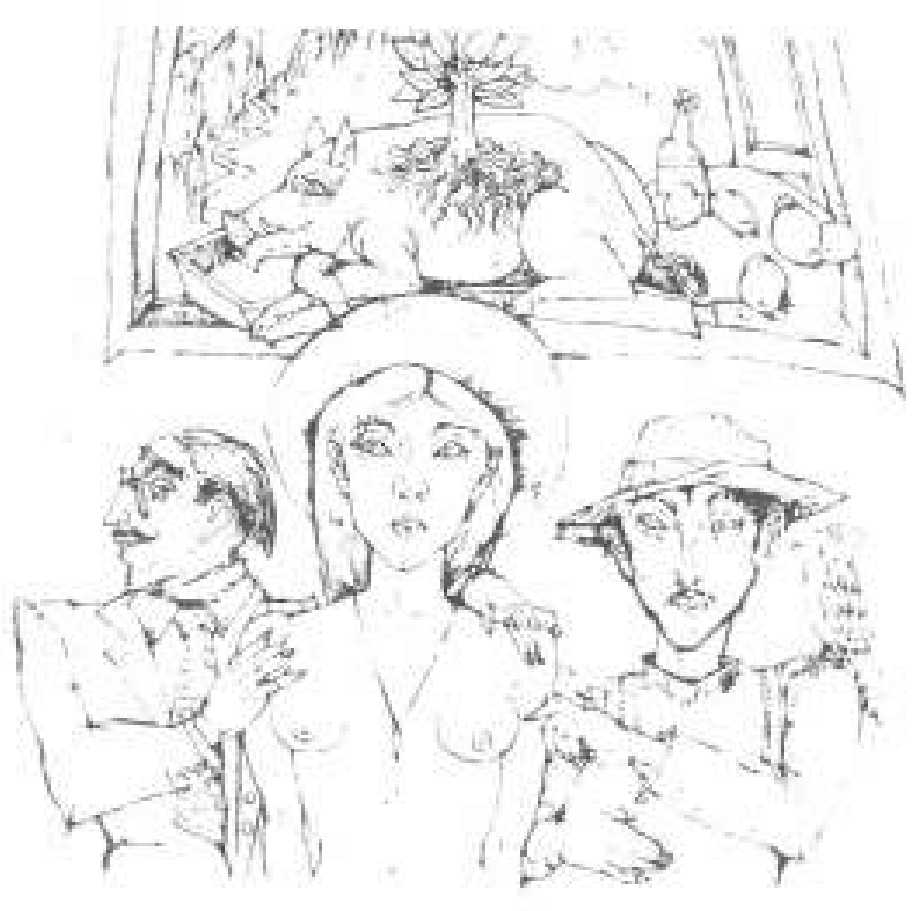

Para mi. la mayor preocupacion era el aprendizaje de las tablas de multiplicar, pues su conocimiento era la base para poder aprobar el año escolar. El maestro, en ocasiones ejercia violencia sobre sus ulumnos, pues por cualquier error cometido el castigo era casi siempre físico, en ocastones ilegaba a ser cruel. Ellos practicaban la metodologia de la ensetianza que habian heredado, generalmente aprobada por nuestros padres, basada en el principio de: "las letras, como la aritmetica, con sangre entran ${ }^{+*}$. Siempre sorié en la existencia de una máquina mágica que, estripándole un botón, hiciera las operaciones que el maestro pedia.

En esa época se oía en la radio y se leia en los periódicos (TV no se tenia todavia) los pros y los contras de la politica populista del caudillo Jorge Eliecer Gaitan, quien denunciaba las irregulandades y atropellos del gobiemo de tumo. Fue asesinado el 9 de Abril de 1948, acontecimiento que tengo muy presente en mi memoria por los sucesos que se presentaron despues, pues en Bogotá y otras ciudades se produjeron asesinatos, incendios y saqueos oca. sionados por sus seguidores. En algunas regiones del pais comenzo la violencia partidista y los campos se bafiaron en sangre por el bandolerismo, pues en aras de enarbolar un color politico asesinaban a los campesinos con las armas mas rudimentarias.

En la década de los cincuenta se produjo cambiode gobiemo, contunuó la violencia rural y llego al poder una nefasta dictadura militar ta cual trajo ta TV estatal, que era controlada por ellos; por tanio. ias noticias eran sometidas a la censura. Fue una epoca de terror y corrupción: hubo masacres estudiantiles. el pueblo se levantó y el dictador tuvo que abdicar, para crearse luego un sistema de gobiemo compartido por los dos partidos politicos tradicionales, denominado Frente Nacional y en el cual existia paridad de puestos en la burocracia, siendo la condición principal para desempeñar una posicion el pertenecer al color politico asignado a dicho puesto. Fueron muchas las personas a quienes se les matriculó en un partido politico por decreto. Asi, el politico de turno repartia tos puestos y colocaba las "fichas claves" para la reparticiôn de los presupuesto5. La violencia partidista continuó y se presentaron casos como el de un bus de la Linversidad de Caldas, interceptado por los bandoleros en el sector de Letras, hecho en el que asesinaron a quien dirigia la orquesta porque al momento de identificarse expresó ser el director del conservatorio de Caldas. Debido a esta violencia se produjo el éxodo masivo de campesinos a las ciudades capitales formândose los llamados cinturones de miseria.

Al comenzar la década de los sesenta, ingresé a la Universidad Nacional seccional Manizales, en la cual la única carrera que existia era ingenjeria civil. cuyo escaso alumnado (menos de 200) era demasiado heterogẻneo tanto a nivel económico como social; habia estudiantes que llegaban en vehiculo último modelo como otros que lo ünico que poseian

\section{Universidad Autónoma de Manizales}


para sus traslados cran zapatos de segundo remonte; pero la unidad era ejemplar, alli se sobresalia por la capacidad intelectual. En la asignatura de aritmetica conoci y estudié las matrices cuadradas y cómo calcular el valor de sus determinantes, para resolver un sistema de ecuaciones lineales por el metodo de Cramer. Debido a la incipiente tecnologia de ayuda en las matematicas, esta labor era de agotadoras jornadas. El Algebra Lineal todavia no pertenecia al pénsum.

En el pais las noticia que se escuchaban sobre la inmoralidad administrativa crecian; los órganos de control en las entidades estatales eran dirigidos por los mismos que gobemabarn; la violencia en los campos continuaba; el campesinado era desarmado por las autoridades y su éxodo hacia las ciudades seguia. Antes de graduarme, me fue ofrecida una posición en el gobiemo municipal, en agradecimiento a los servicios prestados por mi papa al partido. Laborando como ingeniero en la secretaria de obras publicas departamentales, tuve como jefe a un señor que no habia terminado estudios de bachillerato y cuyo unico oficio habia sido el manejo de una distribuidora de cerveza en su municipio, pero el gobemador justificaba su nombramiento diciendo: "que en esa posición necesitaba a alguien que obedeciera, no que pensara", $y$ asi la maquinaria de carreteras estuvo a disposición de los votos.

La tecnologia seguia avanzando; llegaron las maquinas electrónicas que se caracterizaban por ser rapidas y silenciosas, propiedades estas utilizadas por los "servidores" del Estado para dilapidar sus recursos y sus bienes, Los sectores de oposición no prosperaron. El descontento de las gentes aumentaba y fue así como un movimiento populista, en el año de 1.970 , se dice que ganó las elecciones pero no obtuvo la Presidencia de la República. No hubo una oposición constructiva; la rebatiña por los pues- tos y la falta de cumplimiento de las promesas en campaña, lo llevó a su casi desaparición.

Luego, en 1.974 se desmonta el Frente Nacional, sistema al cual se le achacaban mucho de los males que sucedieron en el pais, pero nada cambio en cuanto al mancjo del erario publico. Aquellos que dirigian el pais, con el poder político y económico que habian conseguido, se fueron perpetuando. Se habla de desfalcos, robos, malos manejos, pero todo queda en el olvido, por "falta de pruebas".

La tecnologia sigue avanzando en forma acelerada. Es por ello que en las universidades, en algunas carreras, se introduce en el pensum la catedra de Algebra Lineal, pues operaciones que tardaban en su cjecucion en muchas horas, pueden efectuarsen en pocos minutos. Pero si lo anterior es un avance en el progreso, en el pais ya se habla de narcotráfico, que invade algunas ciudades, creando la cultura del dinero fácil y aumentando la corrupciónen las autoridades civiles y de policia que se ponen a su servicio. Se comenta, tambien, de los negociados de grandes grupos economicos, que dejan en la rui-

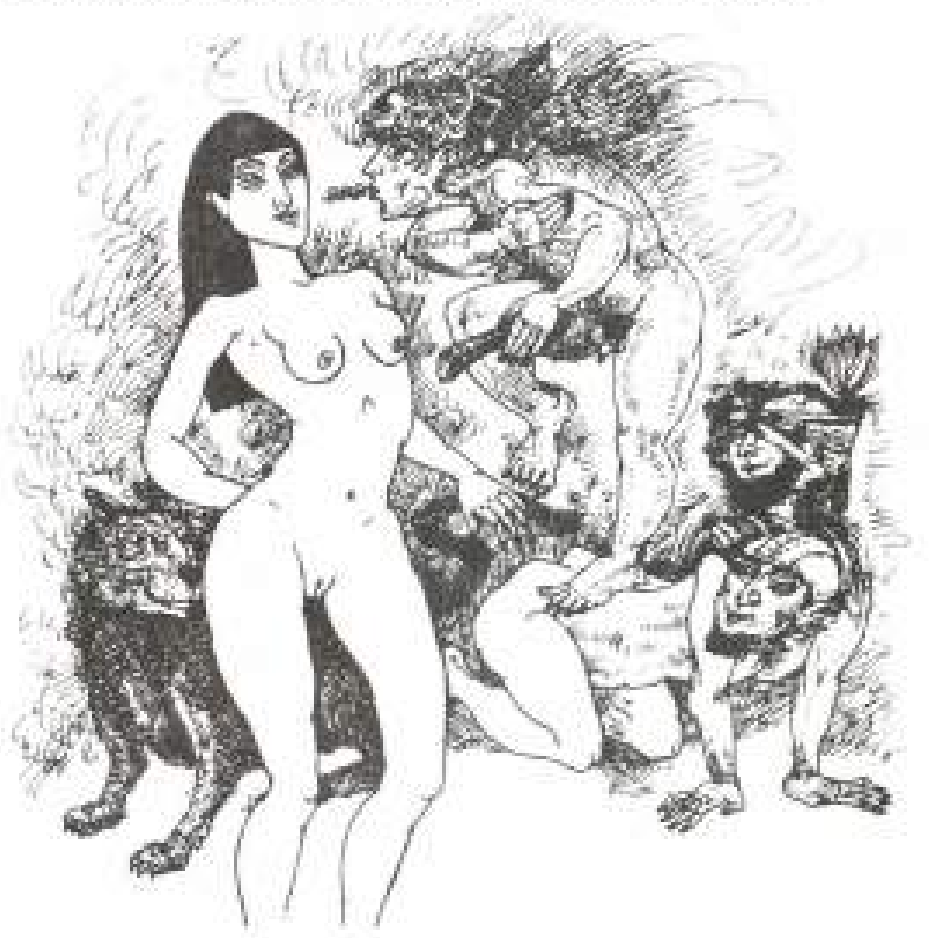


na a cantidad de ahorradores, como también las entidades financieras del Estado que tienden a su ruina por malos manejos de sus directivas y por la complicidad de los organismos de control.

Como si lo anterior fuese poco, también se desata el terronsmo en algunos lugares. No se halla seguridad o tranquilidad ni en los mismos hogares u oficinas. Existe desconfianza hasta en las mismas autoridades de policia; nadie se atreve a hacer denuncias por el temor de que las personas que las reciben estén implicadas en el ilicito, La guerrilla siembra el terror en las carreteras y en tas poblaciones pequenas. Se elige un gobierno con ayuda econimica del narcotrafico. el ministro estrella. quien fue director de la campaña, lo reconoce. El presidente de la república lo niega. La comisión legislativa de acusaciones, lo absuelve. Todo sigue igual de comupto; la Nación no tiene dolientes.

Hay cambio de gobierno; existen esperanzas de mejorar. Pero día a día aumenta el desempleo y. como consecuencia, una recesión no conocida por nuestra generacion. Las necesidades aumentan como tambien la insegundad: las gentes se desesperan. Con escepticismo se oye hablar de pazen este pais catalogado como uno de los más violentos de la tiema.

Analizando lo anterior me pregunto, recordando cuando era nuño. : ¿ ¿ fueron mejores las epocas pasadas: 